\title{
Membrane Fluidity: About the Origin of Autoimmunity
}

\author{
Isolde Riede \\ Independent Cancer Research, Uberlingen, Germany \\ Email: riede@tumor-therapie.info
}

Received 14 December 2013; revised 14 January 2014; accepted 21 January 2014

Copyright (C) 2014 by author and Scientific Research Publishing Inc.

This work is licensed under the Creative Commons Attribution International License (CC BY). http://creativecommons.org/licenses/by/4.0/

(c) (i) Open Access

\section{Abstract/Hypothesis}

Fluidity of cellular membranes is essential for life. Two possibilities are known to keep human membranes fluid: unsaturated fatty acids and cholesterol. Whereas liver cells can synthesize cholesterol, unsaturated fatty acids are essential. Life style in Western civilization leads to deprivation of essential fatty acids, to elevated serum-cholesterol-levels and to autoimmunity. Here the hypothesis is presented, and explains the relationship: deprivation of essential fatty acids lead to imminent quasi-crystallization of the membrane. Serum cholesterol-levels are elevated. Incorporation of cholesterol into membranes enhancing fluidity again, is able to repair the effect. At saturation, repair fails. Quasi-crystallization occurs. Proteins tilt into another conformation. This has not been learned during the "self" recognition process of the immune system during the embryonic phase. Immune system attacks the new conformation as "non-self", autoimmunity emerges.

\section{Keywords}

Membrane Fluidity; Autoimmunity; Essential Fatty Acids; Cholesterol; Protein Conformation

\section{Discussion}

Autoimmune diseases with always new manifestations are described about 50 years. They go along with Western civilization.

All living forms are bound to cells. All cells are enclosed in cellular membranes. Membranes separate inside from outside. They select permeability for molecules, transport nutrition inside and waste products outside; they transport and secret hormones, ensure contacts and communications within cells. Without membranes, life is virtually impossible. Only few molecules are able to permeate passively through the membrane, and most are actively transported with a carrier protein. Carrier proteins recognize and selectively transport components under energy consumption. Cells recognize each other through receptor proteins on their membrane surface. The im- 
mune system distinguishes between "self" and "non-self" structures via specific histocompatibility receptors. Biochemically, membranes are built as phospholipid-bilayers. Bipolar components, with a hydrophilic head and a hydrophobic tail lay as a stable structure (Figure 1). Membranes are fluid in their natural state. Fluidity means that all components can move within the structure. In case of a temperature decrease, without biochemical correction, part of the membrane falls in quasi-crystalline structure. Within a transition temperature of 10 to 20 degrees Celsius, all areas become quasi-crystalline.

Within the transition temperature, carrier proteins tilt from one conformation into another. In "frozen" conformation, original functions of the proteins become obsolete. In addition, the membranes become leaky, components leak that are prerequisite for life. With quasi-crystalline membranes life is not possible [1] [2]. Cells regulate the transition temperature of their membranes with variation of components. Optimal condition is life above the temperature, where crystallization would start. Creatures live in very hot or very cold environment. Each of the creatures owns its own possibility to individually maintain the membrane fluid and intact.

Bacteria with complex life cycle like Borrelia are transfered from mites into vertebrates and vice versa. They drive a special program to fluidize their membrane, when entering the mite. Another program leads to other membrane components, when they enter the vertebrate. Life at $37^{\circ} \mathrm{C}$ needs other requirements; membranes have different components during their life spans.

The transition temperature of the membrane is determined by the molecular components. Saturated fatty acids form straight chains; this quasi-crystallization is easier, the transition temperature is higher. Unsaturated fatty acids in the lipid layer form buckled chains. This membrane quasi-crystallizes slower, the transition temperature is lower. At the body temperature of $37^{\circ} \mathrm{C}$, membranes with saturated fatty acids lead to imminent quasi-crystallization, whereas essential fatty acids leave them fluid. In the human cellular membrane, in addition to the es-

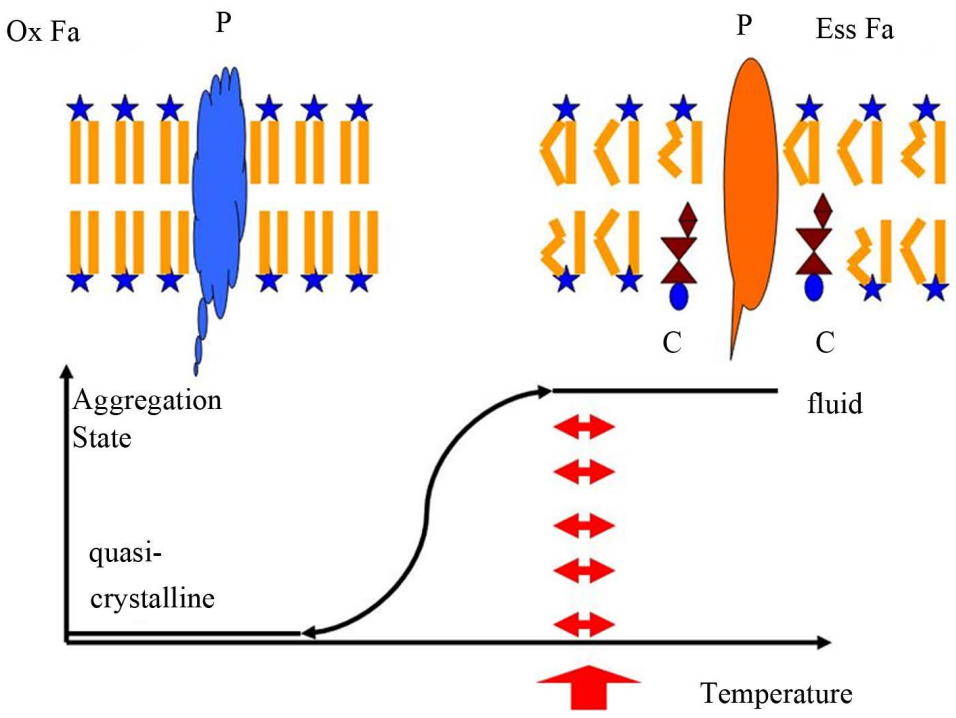

Figure 1. Aggregate states of cellular membranes. A membrane in fluid state is shown as sheme top right. The membrane is built as bilayer, containing lipids with a hydrophilic head (star) and two hydrophobic fatty acids. Hydrophilic heads exhibit to the surface, whereas the hydrophobic fatty acids show in the inner part. Most of the fatty acids here are essential ones, with double bonds, which lead to buckled chains (Ess Fa). This hinders quasi-crystallization. Here some cholesterol molecules (C) in addition enhance fluidity. Herein, a carrier (P) freely moves and can fulfill its task. Top left, a sheme of a quasicrystalline membrane is shown. Saturated fatty acids (Ox Fa) form straight molecules, easy to quasi-crystallize. The carrier tilts into another conformation and has lost its original function. In addition, a new conformation at the outer surface occurs. This new conformation could lead the immune system to attack this structure. The graph below shows the phase-transition of the membrane. The red arrows show the temperature, where life is possible. Life requires complete fluidity. 
sential fatty acids, cholesterol is well known to enhance the fluidity of the structure [3]. Liver cells can synthesize cholesterol.

To explain the etiology of autoimmunity, so far complex mechanisms are discussed, and no visible simple coherence exists. The novel thesis discussed here claims that Western life style leads to deprivation of essential fatty acids. If essential fatty acids are missing, cell membranes are in danger to quasi-crystallize. This induces liver cells to increase serum cholesterol levels to enhance fluidity. With further degradation, this repairs mechanism saturates, and membranes begin to quasi-crystallize. Thereby, proteins in the membrane tilt into a different conformation.

The immune system learns to distinguish between "self" and "non self" during embryogenesis. "Self" recognition is necessary to distinguish between own tissue and agents, that invade the body, and latter have to be recognized, attacked and eliminated. During embryogenesis, the body of the mother supplies essential fatty acids. Rather the mother's body suffers from deprivation than the embryo. Therefore, the immune system learns "self" structures in completely fluid membranes. Conformational change of a protein, due to quasi-crystallization and deprivation of essential fatty acids, will lead to "non self" reaction of the immune system. Autoimmunity emerges. If cells in the Langerhansschen Inseln in pancreas are first attacked, Diabetes occurs. If cells of the joint are affected first, rheumatic disorder occurs.

Cholesterol in cellular membranes increases fluidity, meaning that the body can adapt the membranes to lower temperatures. Cells of a hand are rarely $37^{\circ} \mathrm{C}$ warm, without cholesterol membranes would quasi-crystallize [3]. In case of rheumatic disorder, the colder joints are first affected. In hand, temperatures below $20^{\circ} \mathrm{C}$ can occur, leading to earlier quasi-crystallization than in other tissue with usually higher temperatures.

Deprivation in essential fatty acids leads to imminent quasi-crystallizaion of membranes, and the cholesterol levels are elevated to ensure fluidity. This would mean that high serum cholesterol levels can be lowered by uptake of extra portions of essential fatty acids. This exactly is the case and was shown in several studies [4]-[6].

The upper normal value of cholesterol in human serum was set around 1980 to $100 \mathrm{mg} / \mathrm{dl}$. Meanwhile, it is corrected to $200 \mathrm{mg} / \mathrm{dl}$. The average level of serum cholesterol in the population in Western countries continuously arises. A high serum cholesterol level reflects a deprivation of essential fatty acids in the human population in Western countries. It reflects a risk for quasi-crystallization of membranes. High cholesterol levels are described as risk factors for atherosclerosis, infarction and other autoimmune diseases [7]-[11].

Infectious agents use this Achilles heel for assault. Borrelia uses an enzyme during infection, digesting essential fatty acids [12]. Digesting essential fatty acids diminishes membrane fluidity of the host cell. Additionally, Borrelia can acquire cholesterol from the host cell, and this feature is seen as decisive for the infection success [13]. Transfer from cholesterol from the host to the infectious agent, keeps the membrane of the bacterium fluid, and decreases fluidity of the host membrane. This gives an advantage to the bacterium. In that, the immune response works suboptimal [14]. In addition, cells might become leaky, releasing amino acids and other nutrients to the extracellular liquid, feeding the bacteria. Active borrelioses usually are combined with high cholesterol levels; the body tries to balance the defect. Borrelioses frequently lead to autoimmunity [15]. Here, essential fatty acids digestion, high cholesterol levels and autoimmunity are combined. All three items associate with membrane fluidity.

Why is the Western population deprived in essential fatty acids?

Essential fatty acids are oxidized [16]-[18]. In Western civilization, the pollution of the environment leads to oxidative stress: nitrose or sulfoxide gases and ozone originating from pollution, lead to biochemical oxidation. This leads to free radicals in the body, these oxidize the essential fatty acids in membranes [6]. This leads to a decrease of fluidity.

Western nutrition contains low amount of essential fatty acids. In countries of Southern Europe, autoimmunity is less frequent. There, daily consumption of olive oil is correlated with better health state. In olive oil, in addition to essential fatty acids, polyphenols and Vitamin E occur. Both molecules protect against oxidation of cellular membranes [19]. Nutritional change leads to rare consumption of pure natural foods. Hardened fats, overheated fats, chemicals, drying agents, antidegradants fill nutrition [20]. Overheating fats, i.e. frying french fries, lead to trans-fatty acids. These fatty acids are not natural, and the body cannot digest them. Therefore they are accumulated in the membranes [21] [22].

Which prevention is possible?

All are known already about the prevention against autoimmunity diseases. Avoiding oxidative noxes brings advantage. Sunny summerdays with high ozone levels invite to outdoor activities. It is advantageous to shift 
these activities to the early morning hours, when ozone levels are at a minimum. Additionally, long journeys in motorcars can be avoided, and journeys in trains put less burden on the biochemistry of the human body. Restoring cellular membranes with extra portions of essential fatty acids is advantageous. Natural plant oils, half a liter per week, stabilize fluidity. Primrose oil in addition contains longer chain essential fatty acids. Soja products contain lecithin with essential fatty acids, fish and seafood are sources. Actually lipid exchange therapies, already work successful [23].

How to test the thesis?

Here the thesis is presented that serum cholesterol elevation enhances the fluidity of cellular membranes to repair oxidative damage and deprivation of essential fatty acids. If this is the case, the fluidity of membranes must be measured by a sensor. This sensor should be able to increase in addition the serum cholesterol-level.

Autosomal dominant hypercholesterolemia is caused in $80 \%$ of the cases by mutations in the low density lipoprotein receptor (LDLR) [24]. This receptor is a candidate to measure membrane fluidity and subsequently enhance cholesterol levels. LDLR family is an evolutionarily ancient gene family of structurally closely related cell-surface receptors. Members uptake extracellular ligands and regulate diverse biological processes. They are involved in lipid and vitamin metabolism and cell-surface protease activity. They as well regulate cellular signalling pathways [25]. In that complexity, they are able to fulfill the predicted role as guardians of membrane fluidity, however, their role in measuring fluidity of membranes remains to be detected experimentally.

\section{References}

[1] Overath, P. and Thilo, L. (1978) International Review of Biochemistry, Biochemistry of Cell Walls and Membranes II, 1-44, University Park Press Baltimore.

[2] Wright, J.K., Riede, I. and Overath, P. (1981) Lactose Carrier Protein of Escherichia coli: Interaction with Galactosides and Protons. Biochemistry, 20, 6404-6415. http://dx.doi.org/10.1021/bi00525a019

[3] Alberts, B., Bray, D., Lewis, L., Raff, M., Roberts, K. and Watson, J.D. (1983) Molecular Biology of The Cell, p. 259ff, Garland Publishing Inc., New York \& London.

[4] Agostoni, C., Riva, E. and Biasucci, G. (1992) Fatty Acids in Prevention and Therapy in Pediatrics. La Pediatria Medicae e Chirurgica, 14, 489-494.

[5] Harris, W.S. (2008, 2009) Linoleic Acid and Coronary Heart Disease. Prostaglandins Leukot Essent Fatty Acids, 79, 169-171. Comment in: Prostaglandins Leukot Essent Fatty Acids, 80, 77; Author Reply, 77-78. http://dx.doi.org/10.1016/j.plefa.2008.09.005

[6] Titov, V.N. and Lisitsyn, D.M. (2006) Plasma Content of Cholesterol and Glycerol Alcohols Depends on the Number of Fatty Acid Double Bonds in Lipoprotein Lipid Pool. Bulletin of Experimental Biology and Medicine, 142, 577-580. http://dx.doi.org/10.1007/s10517-006-0422-7

[7] Schmitz, G. and Grandl, M. (2008) Update on Lipid Membrane Microdomains. Search ResultsCurrent Opinion in Clinical Nutrition \& Metabolic Care, 11, 106-112. http://dx.doi.org/10.1097/MCO.0b013e3282f44c2c

[8] McMahon, M. and Hahn, B.H. (2007) Atherosclerosis and Systemic Lupus Erythematosus: Mechanistic Basis of the Association. Current Opinion in Immunology, 19, 633-639. http://dx.doi.org/10.1016/j.coi.2007.11.001

[9] Wick, G. (2000) Atherosclerosis-An Autoimmune Disease Due to an Immune Reaction against Heat-Shock Protein 60. Herz, 25, 87-90. http://dx.doi.org/10.1007/PL00001957

[10] Dalderup, L.M. (1973) Ozone, Vitamin E, Fatty Acids, Prostaglandins, Atherosclerosis and Its Complications. Archives of Environmental Health, 27, 58. http://dx.doi.org/10.1080/00039896.1973.10666311

[11] Titov, V.N., Lisitsyn, D.M., Staroverov, II, Ameliushkina, V.A. and Tvorogova, M.G. (2001) The Content of Double Bonds in Blood Serum Lipids from Patients with Myocardial Infarction. Klinicheskaia Laoratornaia Diagnostika, 12, 3-6.

[12] Yokoyama, M.T. and Davis, C.L. (1971) Hydrogenation of Unsaturated Fatty Acids by Treponema (Borrelia) Strain B 2 5, a Rumen Spirochete. Journal of Bacteriology, 107, 519-527.

[13] Crowley, J.T., Toledo, A.M., LaRocca, T.J., Coleman, J.L., London, E. and Benach, J.L. (2013) Lipid Exchange between Borrelia Burgdorferi and Host Cells. PLOS Pathogens, 9, Article ID: e1003109. http://dx.doi.org/10.1080/00039896.1973.10666311

[14] Ramesh, G., Santana-Gould, L., Inglis, F.M., England, J.D. and Philipp, M.T. (2013) The Lyme Disease Spirochete Borrelia Burgdorferi Induces Inflammation and Apoptosis in Cells from Dorsal Root Ganglia. Journal of Neuroinflammation, 10, 88. http://dx.doi.org/10.1186/1742-2094-10-88

[15] Bolz, D.D. and Weis, J.J. (2004) Molecular Mimicry to Borrelia Burgdorferi: Pathway to Autoimmunity? Autoimmu- 
nity, 37, 387-392. http://dx.doi.org/10.1080/08916930410001713098

[16] Sadowska, J., Johansson, B., Johannessen, E., Friman, R., Broniarz-Press, L. and Rosenholm, J.B. (2008) Characterization of Ozonated Vegetable Oils by Spectroscopic and Chromatographic Methods. Chemistry and Physics of Lipids, 151, 85-91. http://dx.doi.org/10.1016/j.chemphyslip.2007.10.004

[17] Lisitsyn, D.M., Razumovskii, S.D., Tishenin, M.A. and Titov, V.N. (2004) Kinetic Parameters of Oxidation of Individual Fatty Acids with Ozone. Bulletin of Experimental Biology and Medicine, 138, 457-459. http://dx.doi.org/10.1007/s10517-005-0069-9

[18] Ferreri, C. and Chatgilialoglu, C. (2009) Membrane Lipidomics and the Geometry of Unsaturated Fatty Acids from Biomimetic Models to Biological Consequences. Methods in Molecular Biology, 579, 391-411. http://dx.doi.org/10.1007/978-1-60761-322-0_20

[19] Roche, M., Dufour, C., Loonis, M., Reist, M., Carrupt, P.A. and Dangles, O. (2009) Olive Phenols Efficiently Inhibit the Oxidation of Serum-Albumin-Bound Linoleic Acid and Butyryl Cholin Esterase. Biochimica et Biophysica Acta, 1790, 240-248. http://dx.doi.org/10.1016/j.bbagen.2009.01.007

[20] Staprans, I., Pan, X.M., Rapp, J.H. and Feingold, K.R. (2005) The Role of Dietary Oxidized Cholesterol and Oxidized Fatty Acids in the Development of Atherosclerosis. Molecular Nutrition \& Food Research, 49, 1075-1082. http://dx.doi.org/10.1002/mnfr.200500063

[21] Asgary, S., Nazari, B., Sarrafzadegan, N., Parkhideh, S., Saberi, S., Esmaillzadeh, A. and Azadbakht, L. (2009) Evaluation of Fatty Acid Content of Some Iranian Fast Foods with Emphasis on Trans Fatty Acids. Asia Pacific Journal of Clinical Nutrition, 18, 187-192.

[22] Costa, A.G., Bressan, J. and Sabarense, C.M. (2006) Trans Fatty Acids: Foods and Effects on Health. Archivos Latinoamericanos de Nutrición, 56, 12-21.

[23] Nicolson, G.L. and Ash, M.E. (2013) Lipid Replacement Therapy: A Natural Medicine Approach to Replacing Damaged Lipids in Cellular Membranes and Organelles and Restoring Function. Biochimica et Biophysica Acta. http://dx.doi.org/10.1016/j.bbamem.2013.11.010

[24] Awan, Z., Choi, H.Y., Stitziel, N., Ruel, I., Bamimore, M.A., Husa, R., Gagnon, M.H., Wang, R.H., Peloso, G.M., Hegele, R.A., Seidah, N.G., Kathiresan, S. and Genest, J. (2013) APOE p.Leu167del Mutation in Familial Hypercholesterolemia. Atherosclerosis, 231, 218-222. http://dx.doi.org/10.1016/j.atherosclerosis.2013.09.007

[25] Herz, J. and Bock, H.H. (2002) Lipoprotein Receptors in the Nervous System. Annual Review of Biochemistry, 71, 405-434. http://dx.doi.org/10.1146/annurev.biochem.71.110601.135342 